\title{
Grid resonance attenuation in long lines by using renewable energy sources
}

\author{
Raúl Santiago Muñoz-Aguilar \\ Department of Electrical Engineering, \\ Technical University of Catalonia, \\ Terrassa, Spain \\ raul.munoz-aguilar@upc.edu \\ Ignacio Candela \\ Department of Electrical Engineering, \\ Technical University of Catalonia, \\ Terrassa, Spain \\ candela@ee.upc.edu
}

\author{
Joan Rocabert \\ Department of Electrical Engineering, \\ Technical University of Catalonia, \\ Terrassa, Spain \\ rocabert@ee.upc.edu \\ Pedro Rodríguez \\ Loyola Andalucía University \\ Faculty of Engineering, \\ Seville, Spain \\ prodriguez@uloyola.es
}

\begin{abstract}
In this paper the grid harmonic resonance on long lines is studied, in particular the resonance phenomena between the grid series inductance and the line parallel capacitor. Later, the resonance is attenuated by using a renewable energy generator. Experimental results are depicted and the conclusions are stated
\end{abstract}

Keywords—harmonics; resonance; renewable energies; power electronics.

\section{INTRODUCTION}

The power grid is mainly composed by a huge numbers of generators interconnected trough long lines. Due to the line lengths, series inductances and parallel capacitances appears. The series connection of these elements usually generates different harmonic resonances. The actual system is promoted to be a distributed power system in which renewable energy system are taking part in the market. The interaction of the grid filters and cables $\mathrm{s}$ is also bringing harmonic resonances into the system [1]. The problem occurs when the harmonic resonance appears at a frequency that can be excited by the generators, in special by the renewable energy sources, which has a grid-tied inverter in the point of common coupling. The bandwidth of the grid side inverter in renewable systems also allows helping to support the grid, including harmonic compensation.

The harmonic phenomena in power systems is of recent interest. The harmonic phenomena in the Danish system is studied in [2], in this paper, the authors show the power qualities issues and challenges and they have mentioned the influence of grid impedance in harmonic content. The resonances in a distributed system in which several renewable energy sources are connected was studied in [3] and the stabilization with proportional derivative controllers have been researched in [1]. Similar case is the resonant analysis in the voltage controlled distributed generation systems [4].

The harmonic resonances brings as a result the system instability, the stabilization have been done by methods like proportional derivative [1], passivity based methods [5], impedance stability criteria [6], virtual RC damping [7] or active dampers [8]. The resonance stabilization in a railway system were the research focus of [9] in this case the resonance is between the rolling stoch and the infrastructure.

In the actual work the harmonic resonances appearances in a long line is studied. The paper is organized as follows: in section II the scenario under study is presented and the problem stated. In order to compensate the harmonic resonance in the grid, a 4MW wind power system is connected, and the grid side converter control is designed in section III, this control takes into account the harmonic controller and compensator to attenuate the grid resonances. Section IV presents the experimental results; in this experiments the grid is simulated in a real time simulator and the grid side converter is a real one controlled with a digital signal processor. Finally, in section V the work conclusions are stated.

\section{GRID RESONANCE IN LONG LINES}

The system under study is a long line system depicted in Figure 1. It is composed of three buses. An infinite bus of $132 \mathrm{kV}$ is connected to the bus $\mathrm{B}_{0}$ trough line $\mathrm{L}_{0}$. Buses $\mathrm{B}_{0}$ and $\mathrm{B}_{1}$ are interconnected by line $L_{1}$. The buses $B_{1}$ and $B_{2}$ are connected by the line $\mathrm{L}_{2}$ and a transformer which reduces the voltage to $33 \mathrm{kV}$ in the bus $\mathrm{B}_{2}$, in the same bus there is a $20 \mathrm{MW}$ wind power plant. At bus $B_{1}$ it is also connected a $4 \mathrm{MW}$ wind power plant, in this case the voltage is reduced to 0.69 through a transformer; this power plant provide grid support. All the 
lines are modelled using a $\pi$ scheme and the transformers saturation is neglected.

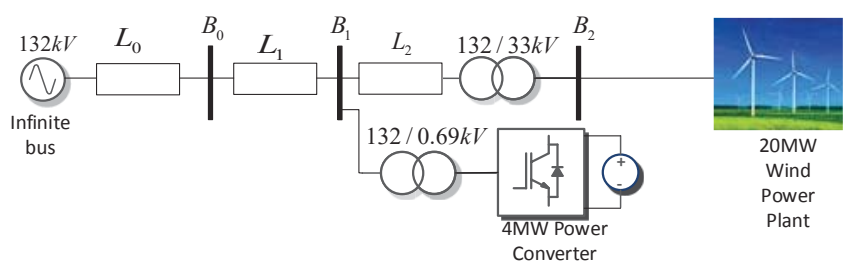

Figure 1 Long line system under study

Due to the long lines distribution and length, a $5^{\text {th }}$ harmonic resonance appears at bus $\mathrm{B}_{1}$ and the disturbances produced by the 20MW wind power plant excites this resonance.

In order to compensate the harmonics on bus $\mathrm{B}_{1}$, the power plant can work as an active filter. The particularity of this filter is that in reality this is a $4 \mathrm{MW}$ wind power plant in which part of the available power is used to compensate the system. Then, in this paper we will focus on the grid side power converter control.

\section{GRID SIDE CONVERTER CONTROL STRATEGY}

The designed current control strategy for the fundamental harmonic is a proportional resonant (PR) with bandwidth which corresponds to the transfer function:

$$
C_{i}(s)=P R=K_{p}+\frac{2 \omega_{c} K_{i} s}{s^{2}+2 \omega_{c} s+\omega_{0}^{2}}
$$

Where $\mathrm{K}_{\mathrm{p}}, \mathrm{K}_{\mathrm{i}}, \omega_{0}$ and $\omega_{\mathrm{c}}$ are the proportional gain, the resonance gain, the resonance frequency and the bandwidth, respectively. The PR controller guarantees grid frequency tracking on the steady state and fast dynamic response.

For the harmonics control, pure resonant controllers are used; a phase compensation at each harmonic controller is empirically computed to improve the harmonic compensation. The pure harmonic transfer function for the harmonic $\mathrm{n}$ is,

$$
C_{i}(s)=\frac{2 K_{i} s(\cos (n \Delta \theta))-\sin ((n \Delta \theta) n \omega)}{s^{2}+(n \omega)^{2}},
$$

Figure 2 shows the bode diagram of the harmonic compensation.

A group of resonant controllers for harmonics $2^{\text {nd }}, 3^{\text {rd }}, 4^{\text {th }}$, $5^{\text {th }}$ and $7^{\text {th }}$ was designed and the bode diagram is depicted in Figure 3. Note the different phase response of each harmonic.

In order to attenuate the harmonic behavior, the current reference is obtained by using the previously design controllers with a unitary feedback. This feedback loop converts the resonant controller in a bandpass filter at the harmonic freiuency. Then, it is possible to have a virtual resistive load tuned at the desired frequency. The attenuation scheme for the n-harmonic is depicted in Figure 4. The output of the harmonic to compensate is added finally to the current reference provided by the reference generator.

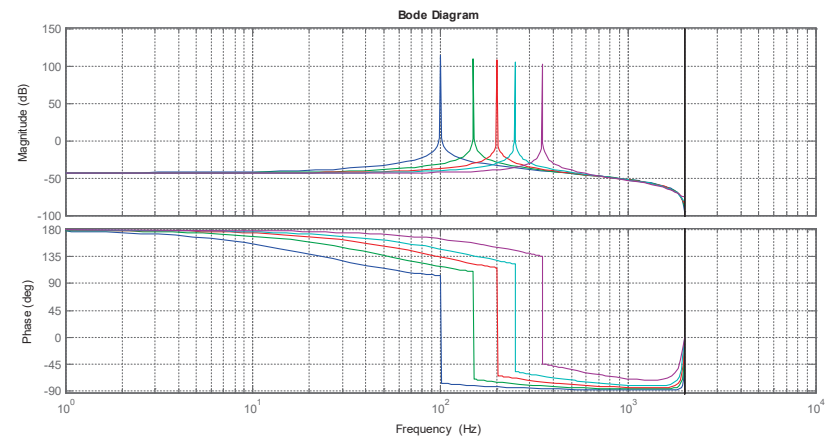

Figure 2 Bode diagram of the harmonic current controllers

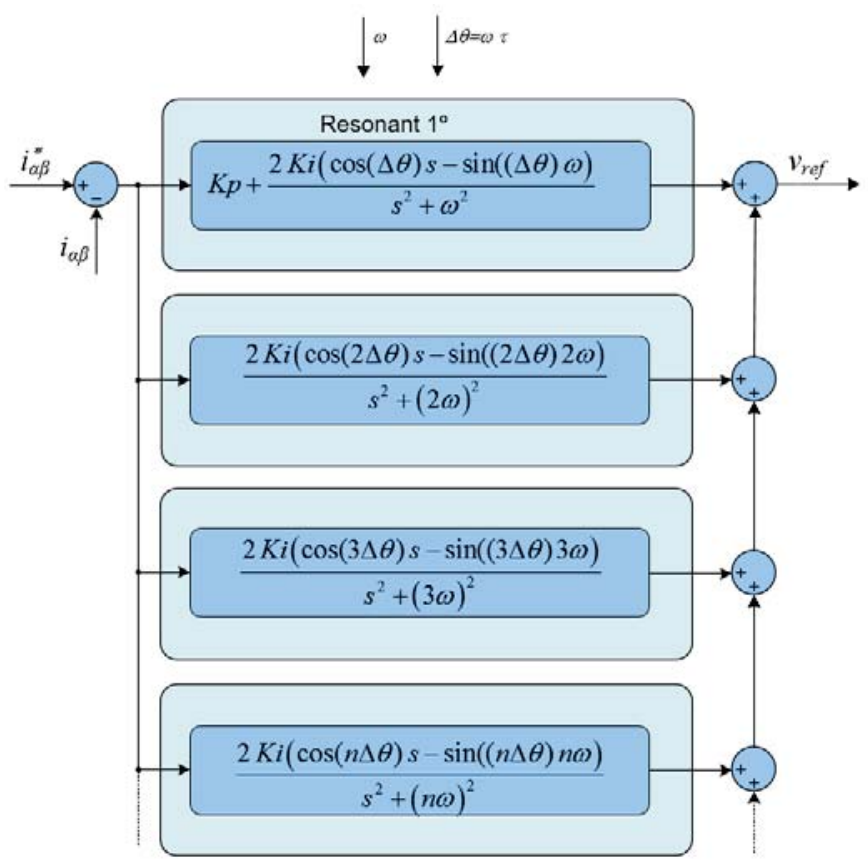

Figure 3 Resonant controllers with delay compensation

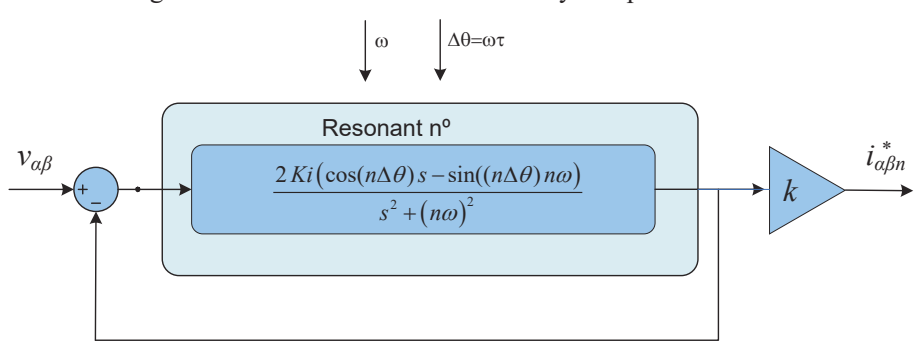

Figure 4 Bandpass resonant for harmonic attenuation 


\section{EXPERIMENTAL RESULTS}

The experimental setup is presented in Figure 5 and its corresponding scheme in Figure 6. The whole grid including buses and transformers is simulated in real time in an OPALRT simulator. This is connected to the real world through a linear power amplifier, which works as connection point to a $10 \mathrm{~kW}$ DSP-controlled power converter, which has the designed controller, and the current output is scaled in the OPAL system to emulate the $4 \mathrm{MW}$ behavior. The inverter is fed by a constant DC source and the Vijeo Citect SCADA System gives the control orders by using Modbus RTU communication protocol.

The system parameters are presented in Table 1 and Table 2

TABLE 1 LINE PARAMETERS

\begin{tabular}{|c|c|c|c|c|}
\hline $\mathbf{R}+(\Omega / \mathrm{km})$ & $\mathbf{R}-(\Omega / \mathrm{km})$ & $\mathrm{L}(\mathrm{H} / \mathrm{km})$ & LO(H/km) & \\
\hline 0,0973 & 0,3864 & 0,00026 & 41,3 & \\
\hline $\mathrm{C}+(\mathrm{F} / \mathrm{km})$ & $\mathrm{CO}(\mathrm{F} / \mathrm{km})$ & LO & L1 & L2 \\
\hline $1,7 \mathrm{E}-07$ & $7,75 \mathrm{E}-06$ & 200 & 4 & 0,1 \\
\hline
\end{tabular}

TABLE 2 TRANSFORMERS PARAMETERS

\begin{tabular}{|l|r|r|r|r|r|l|}
\hline & \multicolumn{1}{|l|}{ S(MVA) } & R1(pu) & L1(pu) & \multicolumn{1}{l|}{ R2(pu) } & \multicolumn{1}{c|}{ L2(pu) } & Conf \\
\hline T1 & 30 & 0,006 & 0,1 & 0,006 & 0,1 & $Y Y n$ \\
\hline T2 & 10 & 0,004 & 0,04 & 0,004 & 0,04 & $Y Y n$ \\
\hline
\end{tabular}

The experiment consist in perturbing the bus $\mathrm{B}_{2}$ injecting current harmonic content with the $20 \mathrm{MW}$ wind power plant. This perturbation generates a resonance in bus $\mathrm{B}_{1}$.

In the first test a $2 \%$ harmonic content is injected as depicted in Figure 7. In this experiment, the voltage total harmonic distortion $\left(\mathrm{THD}_{\mathrm{v}}\right.$ ) becomes $7.8 \%$ and the current total harmonic distortion $\left(\mathrm{THD}_{\mathrm{i}}\right) \mathrm{42.2 \%}$. Once the compensation is activated as depicted in Figure 8 the $\mathrm{THD}_{\mathrm{v}}$ and $\mathrm{THD}_{\mathrm{i}}$ becomes 4.9 and $62 \%$, respectively, showing a $\mathrm{THD}_{\mathrm{v}}$ reduction of around $3 \%$.

As aforementioned, the advantage of this control is the possibility of current injection by the power plant in the meanwhile the harmonic content is compensated. In this case, $5 \mathrm{~kW}$ power reference is injected in bus $\mathrm{B}_{1}$ (equivalent in the simulated grid to $2 \mathrm{MW}$ ) as showed in Figure 9. The $\mathrm{THD}_{\mathrm{v}}$ becomes $3.9 \%$ and the $\mathrm{THD}_{\mathrm{i}} 24 \%$, respectively, showing an extra $\mathrm{THD}_{\mathrm{v}}$ reduction around $1 \%$, it means that the total $\mathrm{THD}_{\mathrm{v}}$ reduction is close to $4 \%$ (near to the $50 \%$ ).

The second test consist in perturbing the bus $\mathrm{B}_{2}$ injecting $3 \%$ current harmonic content with the $20 \mathrm{MW}$ wind power plant. This perturbation generates a resonance in bus $\mathrm{B}_{1}$ as is depicted in Figure 10, the $\mathrm{THD}_{\mathrm{v}}$ becomes $12.3 \%$ and the $\mathrm{THD}_{\mathrm{i}}$ $53 \%$. Once the compensation is activated as depicted in Figure 11 the $\mathrm{THD}_{\mathrm{v}}$ and $\mathrm{THD}_{\mathrm{i}}$ becomes 8.3 and $79 \%$, respectively, showing a $\mathrm{THD}_{\mathrm{v}}$ reduction of around $5 \%$.

When $5 \mathrm{~kW}$ power reference is injected as showed in Figure 12, the $\mathrm{THD}_{\mathrm{v}}$ and the $\mathrm{THD}_{\mathrm{i}}$ becomes 6.9 and $34 \%$, respectively, showing an extra $\mathrm{THD}_{\mathrm{v}}$ reduction around $1.4 \%$, it means that the total $\mathrm{THD}_{\mathrm{v}}$ reduction is close to $6 \%$ (again, near to the $50 \%$ ).

In the last experiment the bus $\mathrm{B}_{2}$ is perturbed injecting 5\% current harmonic content with the 20MW wind power plant. In this condition, when the system is uncompensated, the $\mathrm{THD}_{\mathrm{v}}$ and $\mathrm{THD}_{\mathrm{i}}$ becomes $20.8 \%$ and $69.5 \%$, respectively, as shows Figure 13.

Afterwards, the compensation is activaded in Figure 14 reducing the $\mathrm{THD}_{\mathrm{v}}$ to $13.1 \%$ and the $\mathrm{THD}_{\mathrm{i}}$ get increase to $90.9 \%$. Finally, when $5 \mathrm{~kW}$ of power is injected in bus $\mathrm{B}_{1}$ the $\mathrm{THD}_{\mathrm{v}}$ and $\mathrm{THD}_{\mathrm{i}}$ arrives to 13.3 and $46.6 \%$, respectively. It shows that the power compensation can be carry out and when the perturbation is too high, the correction is similar with and without power injection.

Table 3 and Table 4 present a resume of the THDv and $\mathrm{THD}_{\mathrm{i}}$ for the different perturbations without compensation (NC), with compensation (C) with power reference equal to zero (P0) and equal to $5 \mathrm{~kW}(\mathrm{P} 5)$.

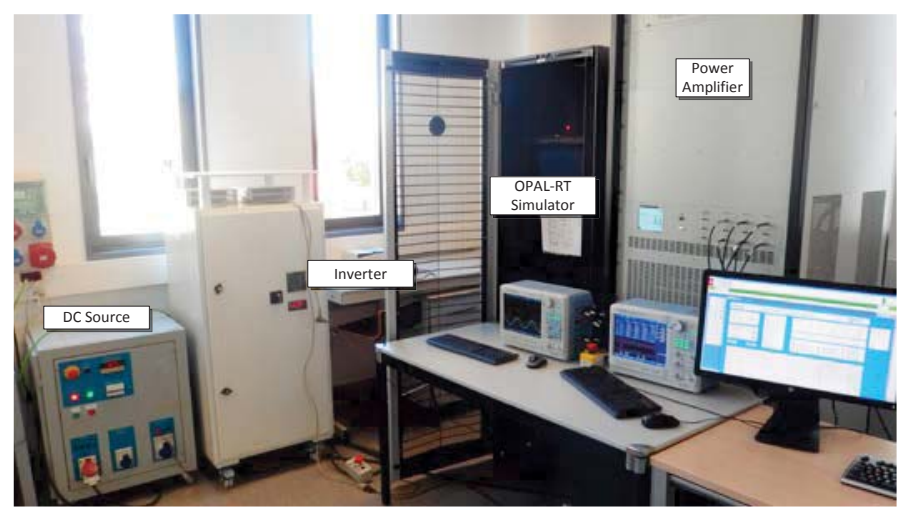

Figure 5 Experimental Setup

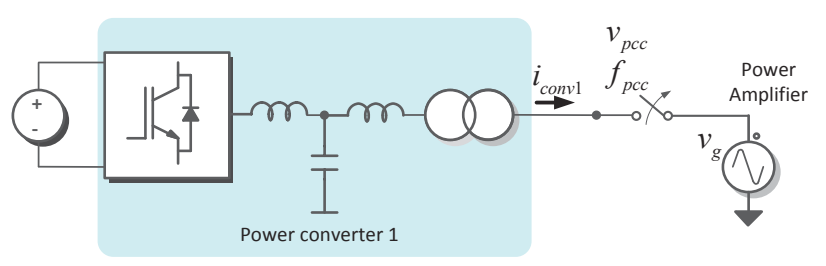

Figure 6 Experimental Setup scheme

TABLE 3 THDV FOR SEVERAL TESTS

\begin{tabular}{|r|r|r|r|}
\hline Pert \% & NC P0 & \multicolumn{1}{l|}{ C P0 } & C P5 \\
\hline 2 & 7,839 & 4,877 & 3,899 \\
\hline 3 & 12,327 & 8,322 & 6,878 \\
\hline 4 & 20,823 & 13,127 & 13,453 \\
\hline
\end{tabular}

TABLE 4 THDI FOR SEVERAL TESTS

\begin{tabular}{|r|r|r|r|}
\hline Pert \% & NC P0 & C P0 & C P5 \\
\hline 2 & 42,252 & 61,987 & 24,049 \\
\hline 3 & 53,274 & 78,829 & 33,842 \\
\hline 4 & 69,542 & 90,923 & 46,632 \\
\hline
\end{tabular}



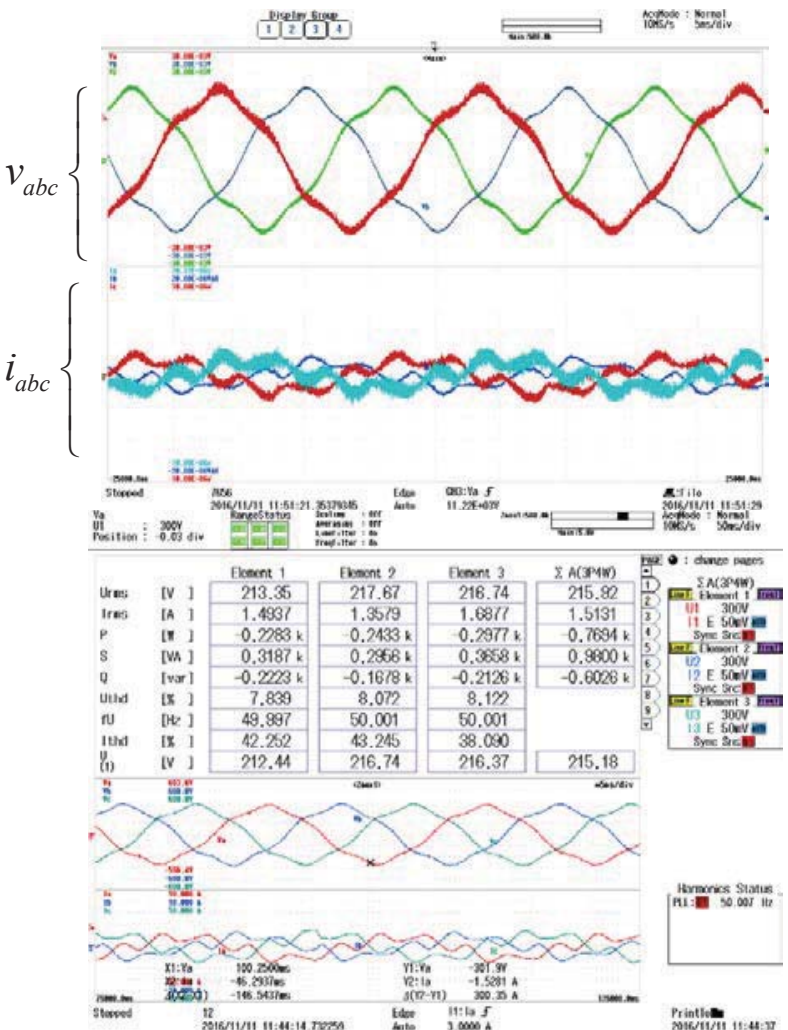

Figure 7 Phase voltages and injected current in bus B1 (left), voltage, current, power and THD data and phase voltages and line currents in the connection point (right) with a perturbation of $2 \%$ in bus B2, uncompensated results.

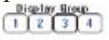
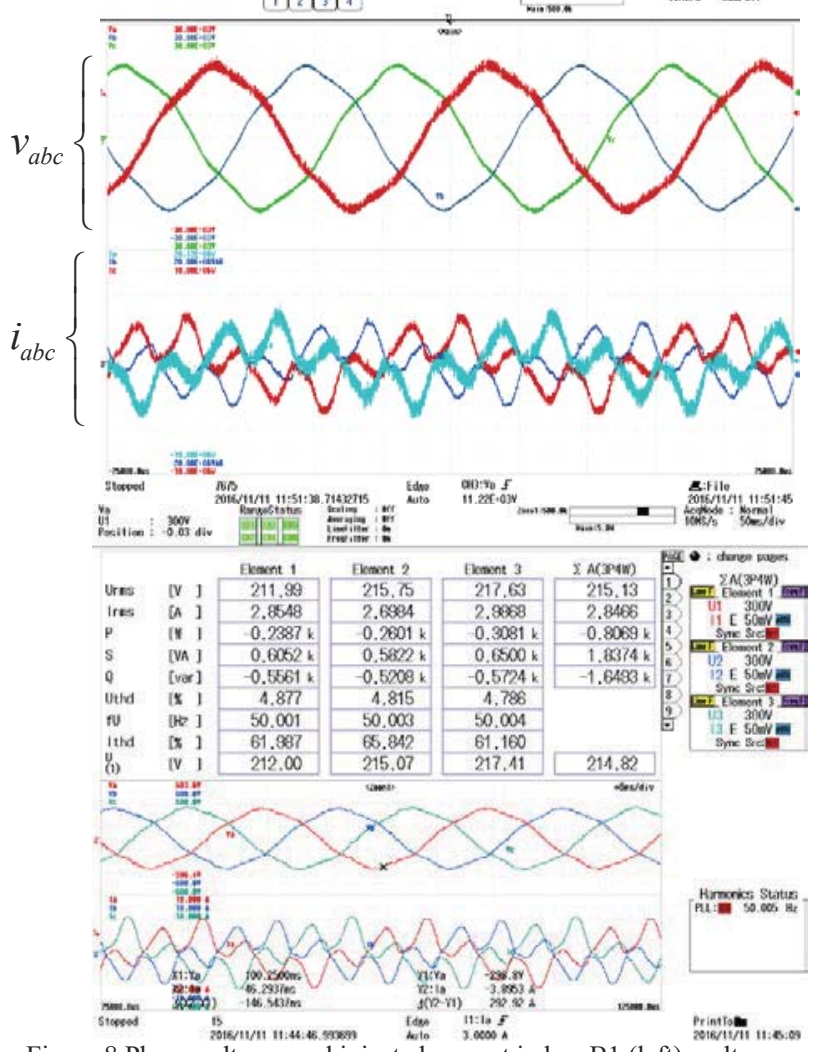

Figure 8 Phase voltages and injected current in bus B1 (left), voltage, current, power and THD data and phase voltages and line currents in the connection point (right) with a perturbation of $2 \%$ in bus B2, compensated results.
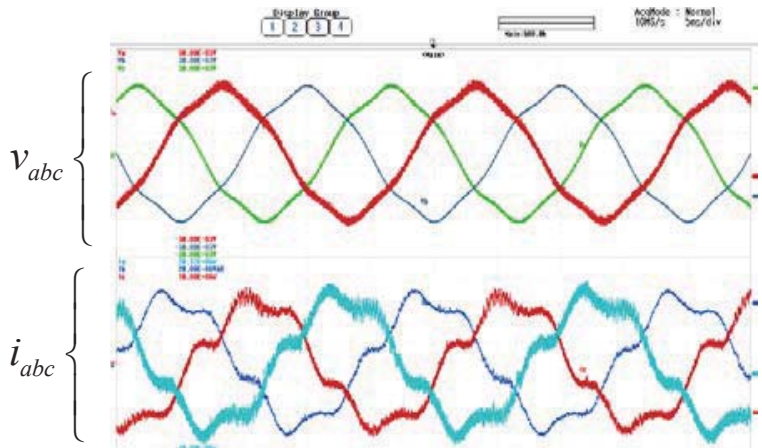

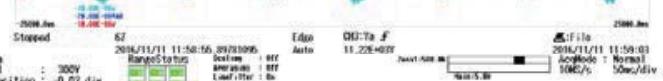

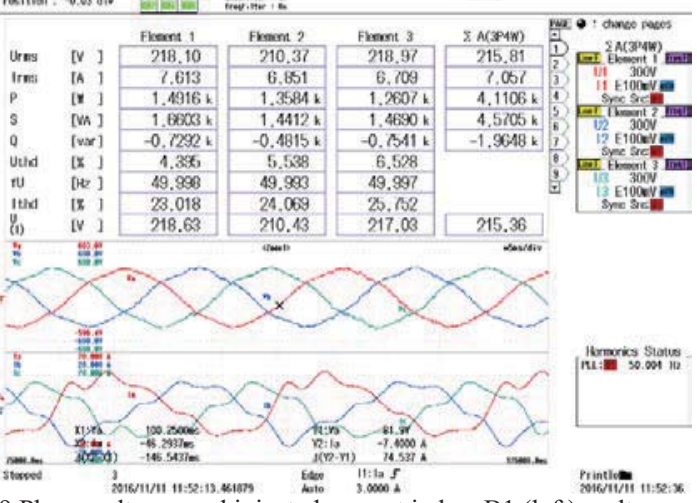

Figure 9 Phase voltages and injected current in bus B1 (left), voltage, current, power and THD data and phase voltages and line currents in the connection point (right) with a perturbation of $2 \%$ in bus B2, compensated results with a power reference of $5 \mathrm{~kW}$.

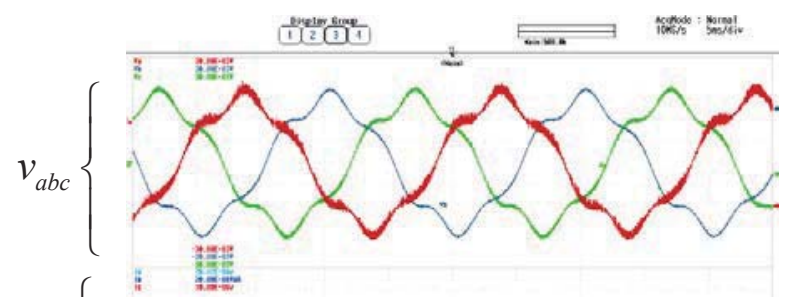

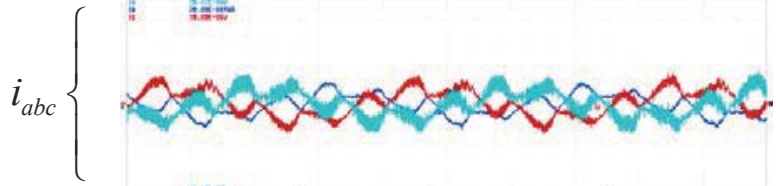

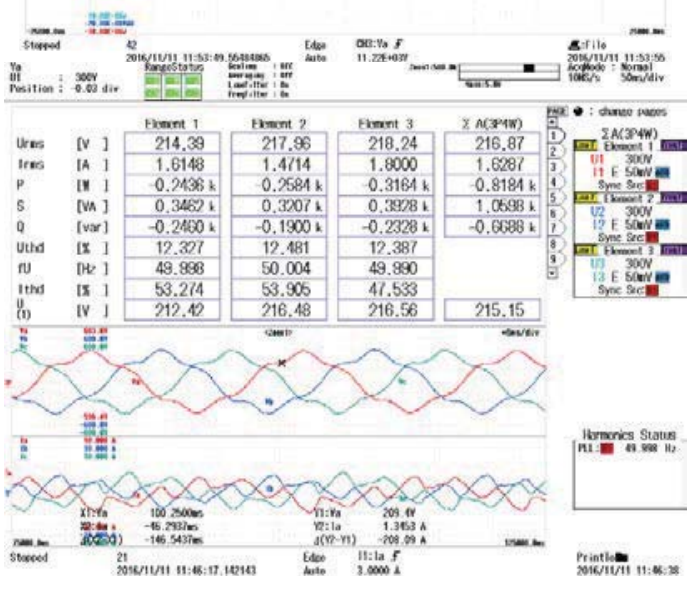

Figure 10 Phase voltages and injected current in bus B1 (left), voltage, current, power and THD data and phase voltages and line currents in the connection point (right) with a perturbation of $3 \%$ in bus B2, uncompensated results. 

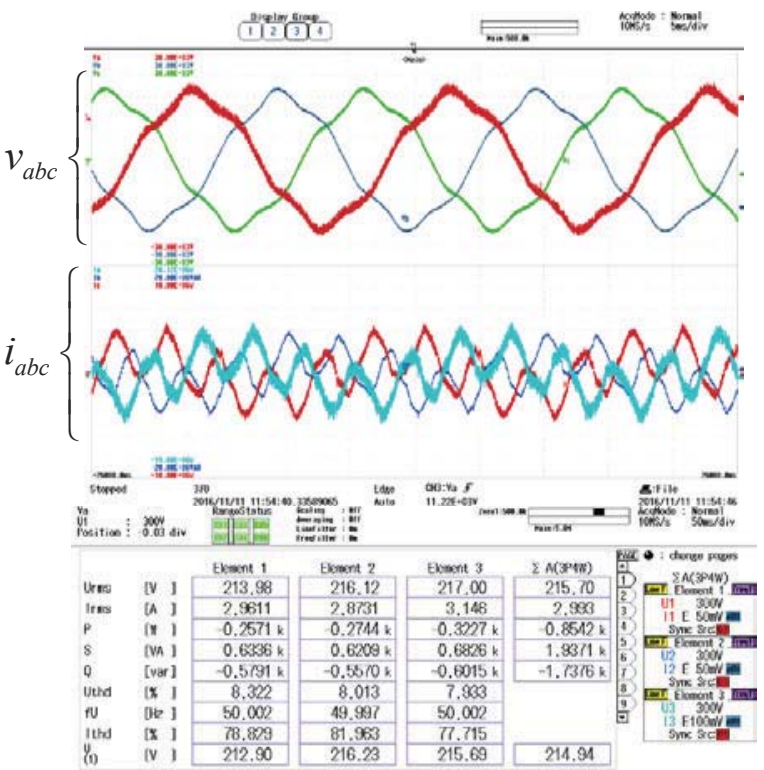

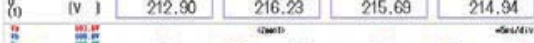

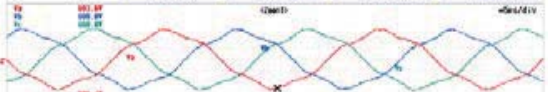

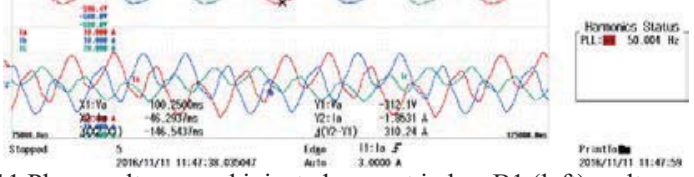

Figure 11 Phase voltages and injected current in bus B1 (left), voltage, current, power and THD data and phase voltages and line currents in the connection point (right) with a perturbation of $3 \%$ in bus B2, compensated results.
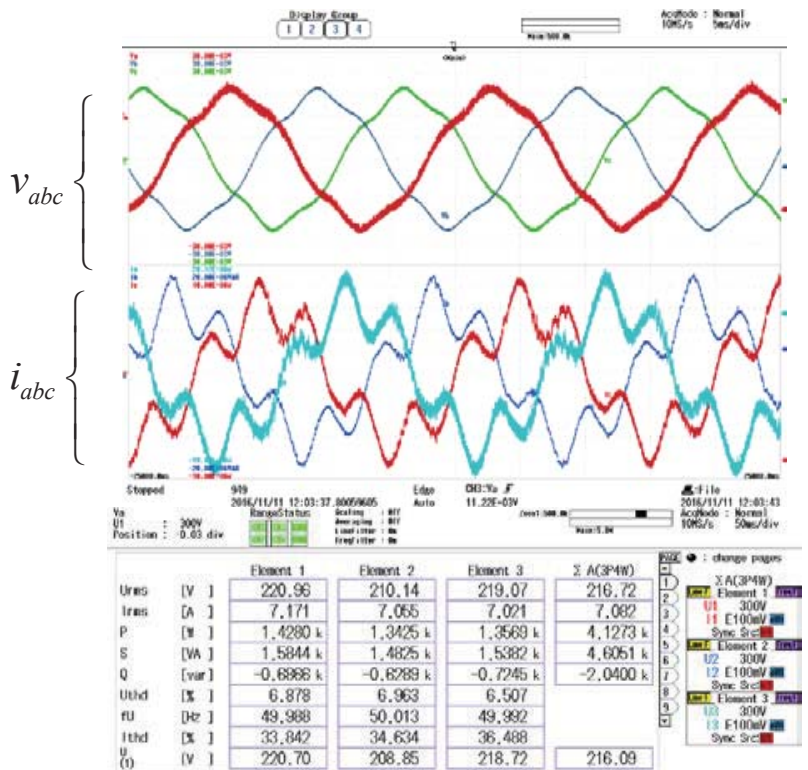

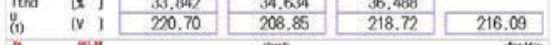

(i)

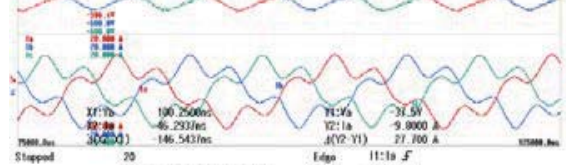

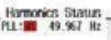

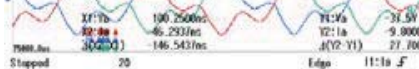

Figure 12 Phase voltages and injected current in bus B1 (left), voltage, current, power and THD data and phase voltages and line currents in the connection point (right) with a perturbation of $3 \%$ in bus B2, compensated results with a power reference of $5 \mathrm{~kW}$.
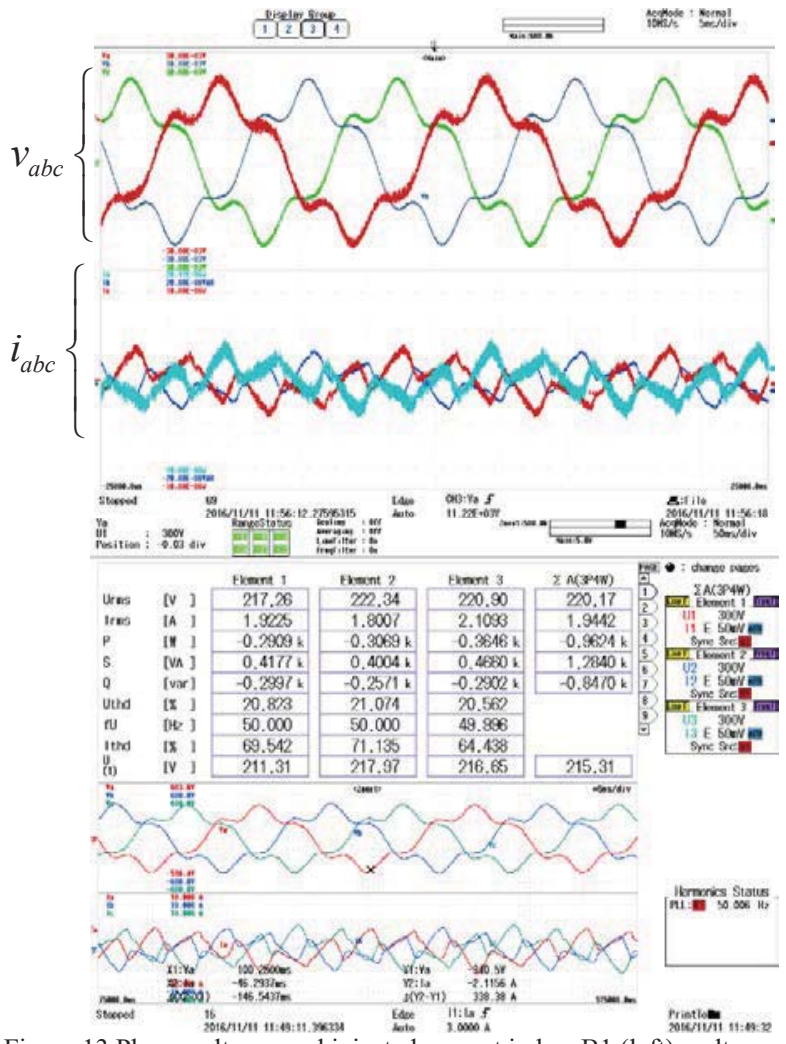

Figure 13 Phase voltages and injected current in bus B1 (left), voltage, current, power and THD data and phase voltages and line currents in the connection point (right) with a perturbation of $5 \%$ in bus B2, uncompensated results
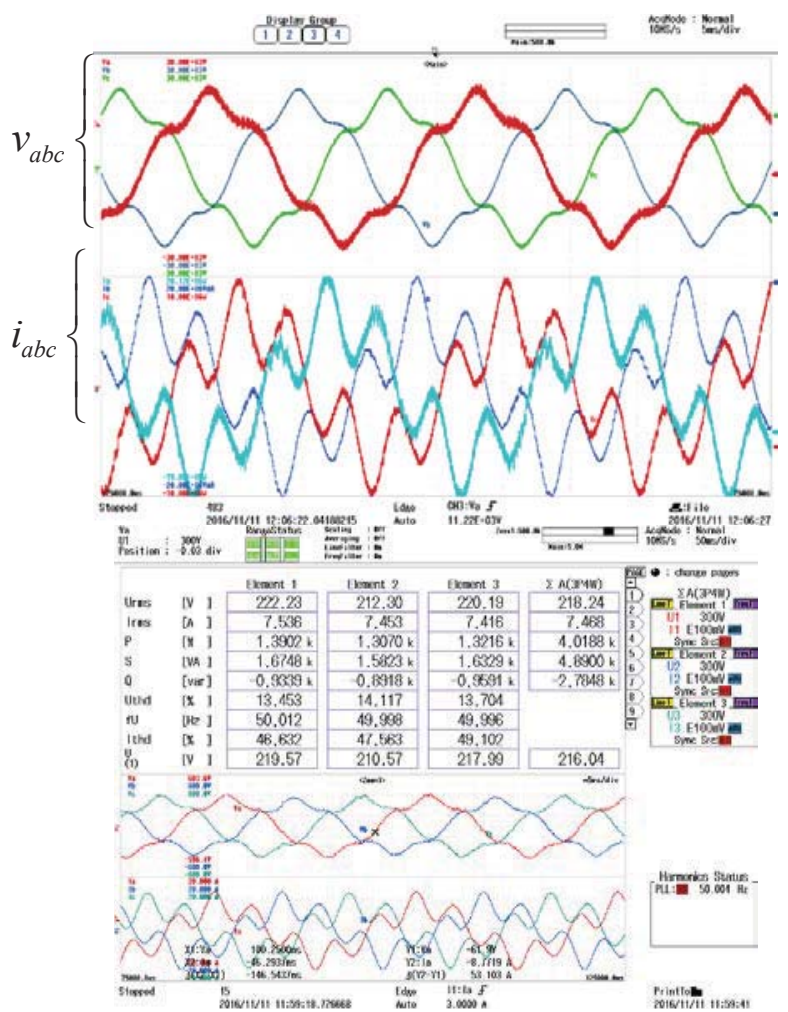

Figure 14 Phase voltages and injected current in bus B1 (left), voltage, current, power and THD data and phase voltages and line currents in the connection point (right) with a perturbation of $5 \%$ in bus B2, compensated results. 

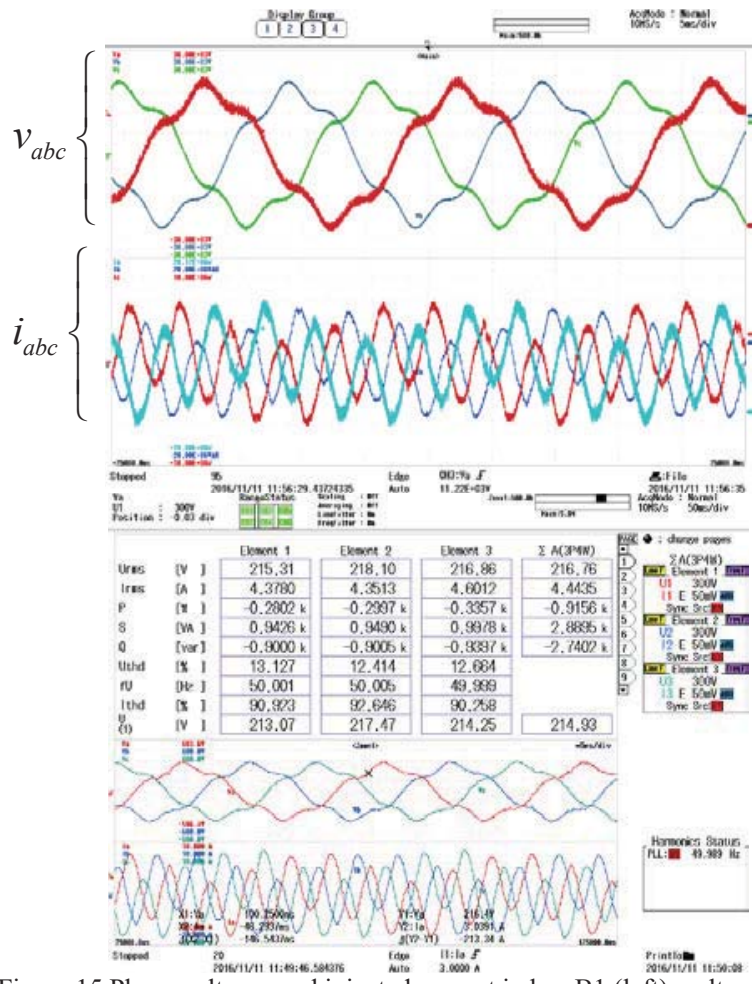

Figure 15 Phase voltages and injected current in bus B1 (left), voltage, current, power and THD data and phase voltages and line currents in the connection point (right) with a perturbation of $5 \%$ in bus B2, compensated results with a power reference of $5 \mathrm{~kW}$.

\section{CONCLUSIONS}

Due to the circuit distribution in long lines, it is possible to appear harmonic resonances into the grid because of the series inductance and parallel capacitance values. This harmonics can be excited by the renewable energy sources trough the grid side power converters.

The proposed control strategy allows controlling de grid harmonic content; in particular attenuate the harmonic resonances into the grid keeping the grid power injection. It means a renewable power plant can compensate the grid harmonics during its normal power generation.

In future works the comparison in the converter behavior with different bus connection points to select the optimal connection point will be studied.

\section{ACKNOLEDGMENT}

This work was supported in part by the projects ENE201460228-R, ENE2016-79493-R and RTC-2016-5024-3 of Spanish Ministry of Economy, Industry and Competitiveness.

\section{REFERENCES}

[1] X. Wang, F. Blaabjerg, and P. C. Loh, "Proportional derivative based stabilizing control of paralleled grid converters with cables in renwable power plants," 2014 IEEE Energy Convers. Congr. Expo. ECCE 2014, pp. 4917-4924, 2014.

[2] C. F. Jensen, "Harmonic Assessment in a Modern Transmission Network," 2015.

[3] J. H. R. Enslin and P. J. M. Heskes, "Harmonic interaction between a large number of distributed power inverters and the distribution network," IEEE Trans. Power Electron., vol. 19, no. 6, pp. 1586-1593, 2004.

[4] X. Wang, F. Blaabjerg, Z. Chen, and W. Wu, "Resonance analysis in parallel voltage-controlled Distributed Generation inverters," Conf. Proc. - IEEE Appl. Power Electron. Conf. Expo. - APEC, pp. 2977 2983, 2013

[5] G. V. A. Overview, L. Harnefors, S. Member, X. Wang, A. G. Yepes, and F. Blaabjerg, "Passivity-Based Stability Assessment of," vol. 4, no. 1, pp. 116-125, 2016.

[6] C. Yoon, H. Bai, R. N. Beres, X. Wang, C. L. Bak, and F. Blaabjerg, "Harmonic stability assessment for multiparalleled, grid-connected inverters," IEEE Trans. Sustain. Energy, vol. 7, no. 4, pp. 1388-1397, 2016.

[7] X. Wang, F. Blaabjerg, and P. C. Loh, "Virtual RC Damping of LCL Filtered Voltage Source Harmonic Compensation," IEEE Trans. Power Deliv., vol. 30, no. 9, pp. 4726-4737, 2015.

[8] X. Wang, F. Blaabjerg, M. Liserre, Z. Chen, J. He, and Y. Li, "An active damper for stabilizing power-electronics-based AC systems," IEEE Trans. Power Electron., vol. 29, no. 7, pp. 3318-3329, 2014.

[9] I. Pendharkar, "Resonance stability in Electrical Railway Systems - a dissipativity approach,”pp. 4574-4579, 2013. 